\title{
Representações sobre a escola ideal para adolescentes dos anos finais do ensino fundamental em contexto de medida socioeducativa de internação
}

Sabrina Cecília Moraes Bastos"

Cátia de Azevedo Fronza**

\section{Resumo}

Os atos infracionais cometidos por adolescentes no Brasil podem ser indicadores de um acesso restrito a direitos fundamentais, à cidadania e à justiça social. A escolarização de adolescentes em medida socioeducativa de internação integra o complexo panorama de adolescentes nos anos finais do ensino fundamental. Face a essa realidade, o objetivo deste artigo é analisar duas representações verbo-visuais sobre a escola ideal, produzidas por adolescentes de uma escola inserida em uma grande unidade de internação socioeducativa do sul do país. Os registros em análise apontam para problemas relativos a escola, juventudes e violência. Destaca-se, assim, a importância de a prática docente dialogar com a historicidade expressa na/ pela linguagem dos jovens, especialmente no espaço socioeducativo, para que boas oportunidades de ensino e de aprendizagem se constituam como práticas concretas e efetivas.

Palavras-chave: Linguagem. Verbo-visualidade. Adolescentes em conflito com a lei. Socioeducação. Ensino fundamental.

\section{Introdução}

Os atos infracionais cometidos por adolescentes no Brasil podem ser indicadores de um acesso restrito a direitos fundamentais, à cidadania e à justiça social, pois o ato infracional não é algo que está no adolescente. O ato infracional está na sociedade, integrado à dinâmica social (VOLPI, 2019). A escolarização de adolescentes em cumprimento de medida socioeducativa de internação integra o complexo panorama de escolarização de adolescentes nos anos finais do ensino fundamental.

\footnotetext{
Doutoranda do Programa de Pós-Graduação em Linguística Aplicada da Unisinos. Docente na Rede Pública Estadual do Rio Grande do Sul em Escola de Atendimento Socioeducativo. E-mail: scmbastos@gmail.com

** Doutora em Letras PUCRS (1999). Docente do Curso de Letras e do Programa de Pós-Graduação em Linguística Aplicada da Unisinos. E-mail: catiaaf@unisinos.br
}

Data de submissão: set. 2020 - Data de aceite: nov. 2020 http://dx.doi.org/10.5335/rdes.v16i3.11468 
O Estatuto da Criança e Adolescente (ECA) (BRASIL, 1990) conceitua ato infracional como uma conduta descrita como crime ou contravenção penal. Com base nesse conceito, estabelece as medidas que a autoridade competente poderá aplicar ao adolescente, havendo, entre outras, a medida socioeducativa de internação em estabelecimento educacional. Tal medida é de privação de liberdade, conforme o próprio Estatuto informa. Medidas socioeducativas são medidas jurídicas, com finalidade pedagógica, aplicadas a adolescentes que incidem na prática de atos infracionais. Essa denominação considera a condição peculiar de pessoa em desenvolvimento do adolescente, em atenção às definições constitucionais, pois, "em lugar de penas, atribui à punição um caráter predominantemente educativo" (CRAIDY, 2012, p. 49).

Bozza (2012) observa que, na rotina da internação, a escola é a principal atividade dos adolescentes, que motiva/ possibilita a saída do dormitório para a sala de aula. A escola, para esses jovens, assume diferentes papéis e sentidos, pois a privação de liberdade, sob essa perspectiva, é uma forma de vigilância e punição. Bastos (2019) identificou que a visão negativa que os adolescentes tinham da escola não era somente no espaço de internação, mas também da "escola da rua", modo como os adolescentes chamam as escolas para o público em geral. Essa visão negativa demonstrou uma relação dialógica com processos de exclusão, risco e vulnerabilidade social.

Para Comerlato (2015, p. 94), uma educação voltada aos interesses e necessidades das classes populares pode motivar melhores resultados em termos de aprendizagens e construção de cidadanias. Wilson (2007) apresenta a noção de "educentricidade" nas ações educacionais em contextos de privação de liberdade no sentido de que as práticas educacionais e, por extensão, as práticas de letramento escolar estão centradas no que um determinado grupo pensa que a educação é ou deveria ser, a partir do que tal grupo considera ser relevante.

O objetivo deste artigo é analisar duas representações verbo-visuais sobre a escola ideal, produzidas por adolescentes dos anos finais do ensino fundamental, em cumprimento de medida socioeducativa de internação, como elemento que pode possibilitar a identificação de temáticas e abordagens de ensino mais significativas para esses adolescentes.

Os dados foram gerados durante 0 desenvolvimento do projeto "Novos Significados para Alunos dos Anos Finais do Ensino Fundamental no Contexto da Socioeducação: linguagens para autonomia e cidadania"1, em andamento.

A reflexão que se faz no âmbito deste artigo insere-se no campo de estudos da Linguística Aplicada, porque se volta à linguagem em uso, buscando refletir 
criticamente, visando resultados que possam apontar soluções alternativas para problemas na sociedade (OSTERMANN; GUIMARÃES, 2019).

Sob essa perspectiva, a reflexão teórica inicia com foco na Teoria das Representações Sociais (JODELET, 1993). Na sequência, destaca-se a verbo-visualidade em perspectiva dialógica (BAKHTIN, 2006). Depois disso, abordam-se concepções sobre escola, juventudes e violência (LACERDA; AMARAL, 2018; GADEA et $a l ., 2017)$, pois estes refletem os objetos de representação evidenciados nos dados. Na seção sobre a metodologia, apresentamos o contexto e participantes do estudo e descrevemos o processo de geração de dados. Na sequência nos voltamos para a análise de duas representações multimodais dos adolescentes, com base nos autores expostos em nossa discussão teórica, encaminhando as reflexões finais geradas no âmbito deste texto.

\section{Teoria das \\ Representações Sociais}

A representação social é "uma forma de conhecimento, socialmente elaborado e compartilhado, que tem um objetivo prático e concorre para a construção de uma realidade comum a um conjunto social" (JODELET, 1993, p. 5). Embora seja um conhecimento que se diferencie do conhecimento científico, pois é chamado também de "saber de senso comum", "saber ingênuo", "natural", a representação social é considerada um objeto de estudo tão legítimo quanto o científico. Sua legitimidade fundamenta-se por sua importância na vida social, em razão do que pode informar a respeito dos processos cognitivos e das interações sociais (JODELET, 1993). Assim, a noção de representação atravessa todas as disciplinas e proporciona uma "visão global do que seja o homem e seu mundo de objetos" (JODELET, 2018, p. 426).

As representações sociais são sistemas de significações que permitem interpretar o curso dos acontecimentos e das relações sociais. Sob essa perspectiva, expressam a relação que os indivíduos e os grupos mantêm com seu "mundo de vida" e os outros atores sociais. Em adição a isso, são formadas na interação e em contato com discursos em circulação no espaço público, estão inscritas na linguagem e nas práticas e funcionam como linguagem em razão de sua função simbólica e dos referentes que elas fornecem para codificar e categorizar o que povoa o universo de vida (JODELET, 2018).

Tomadas como uma forma de saber prático, as representações acarretam uma relação indissociável entre um sujeito e um objeto. "Representar ou se representar corresponde a um ato de pensamento pelo qual o sujeito relaciona-se a um objeto" (JODELET, 1993, p. 5), por isso não existe representação sem objeto. 
A Figura 1, a seguir, ilustra as relações entre sujeito, objeto e representação assumidas neste artigo.

Figura 1 - Relações entre sujeito, objeto e representação

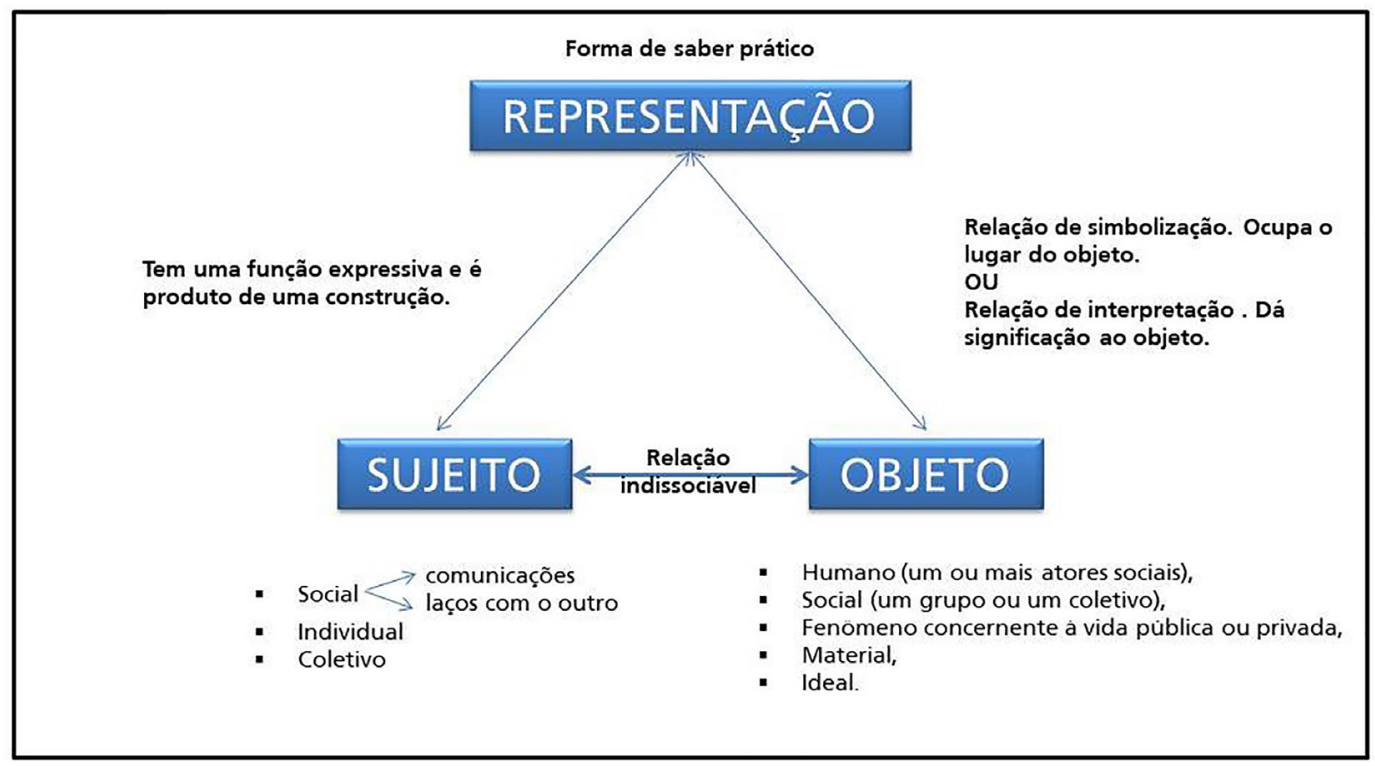

Fonte: Bastos (2019, p. 73), elaborado com base em Jodelet (2018).

Com base na Figura 1, verifica-se que o sujeito é caracterizado como social por sua inserção no espaço das relações sociais, das comunicações e por seus laços com o outro. $\mathrm{O}$ sujeito social pode ser um indivíduo ou um coletivo, sob um ponto de vista epistêmico, psicológico ou pragmático. $\mathrm{O}$ objeto pode ser caracterizado como humano, ou social (um grupo ou um coletivo, ou um fenômeno concernente à vida pública ou privada), ou ainda ser de ordem material ou ideal. Em relação ao objeto, a representação tem função simbólica, pois ocupa o lugar do objeto, ou de interpretação, dá significação ao objeto. Quando se refere ao sujeito, a representação exerce uma função expressiva e é o produto de uma construção (JODELET, 2018).

No campo teórico das representações sociais é importante destacar a noção de experiência, que é um elemento que comporta uma dimensão cognitiva, pois favorece "a experimentação do mundo sobre o mundo e concorre para a construção da realidade, segundo categorias que são socialmente dadas" (JODELET, 2017, p. 438). Assim sendo, a experiência tem relação com os fenômenos representativos, pois 
os termos em que são formuladas essa experiência e sua correspondência com a situação em que ela emerge serão emprestados de pré-construções culturais e de um estoque comum de saberes que lhe darão forma e conteúdo (JODELET, 2017, p. 438).

A experiência constitui o sentido que o sujeito atribui aos fatos, situações, objetos e pessoas que com ele convivem e seu mundo de vida, relacionado ao mundo comum, comunicado por intermédio da linguagem. Assim, compreender que o sujeito é um pensador ativo, conformado na interação com outros em contextos que se situam social e historicamente, é de fundamental importância, quando o objetivo é compreender como uma determinada realidade se constrói.

\section{A verbo-visualidade em perspectiva dialógica}

Com relação à verbo-visualidade, tomamos por princípio a ideia de que

[...] todo fenômeno que funciona como signo ideológico tem uma encarnação material, seja como som, como massa física, como cor, como movimento do corpo ou como outra coisa qualquer (BAKHTIN/VOLOCHINOV, 2006, p. 33).

Além disso, Bakhtin/Volochinov (2006, p. 36) considera a materialidade do signo em geral e não somente do signo verbal:

Os signos são o alimento da consciência individual, a matéria de seu desenvolvimento, e ela reflete sua lógica e suas leis. A lógica da consciência é a lógica da comunicação ideológica, da interação semiótica de um grupo social. Se privarmos a consciência de seu conteúdo semiótico e ideológico, não sobra nada. A imagem, a palavra, o gesto significante, etc. constituem seu único abrigo. Fora desse material, há apenas o simples ato fisiológico, não esclarecido pela consciência, desprovido do sentido que os signos lhe conferem.

A dimensão verbo-visual de um enunciado corresponde à dimensão em que tanto a linguagem verbal quanto a visual desempenham um papel constitutivo na produção de sentidos ou de efeitos de sentido. Como a verbo-visualidade se dá a ler/ver de modo simultâneo, não é possível dissociar o verbal do visual, pois há o risco de extirparmos uma parte da expressão e eliminar a possibilidade de compreender as formas de produção de sentido do enunciado (BRAIT, 2013).

O enunciado verbo-visual, enquanto conjunto, na perspectiva dialógica, em seu caráter enunciativo-discursivo, é revelador de autoria, de diferentes tipos de interlocuções e de discursos. Tais possibilidades de diálogo tornam evidentes aspectos de tensão nas relações, por meio da confrontação entre o verbal e o visual, os quais se mostram como alteridades, pois, ao se defrontarem, constituem memórias de sujeitos e de objetos, possibilitando o surgimento de novas identidades (BRAIT, 2013).

Baronas, Araújo e Ponsoni (2013) chamam atenção para o fato de que as relações dialógicas entre enunciados e discursos têm dois lados que formam a 
natureza do enunciado: o dado e o criado. A esse respeito, Bakhtin (2016, p. 95) explica que:

[...] o enunciado nunca é apenas um reflexo, uma expressão de algo já existente fora dele, dado e acabado. Ele sempre cria algo que não existia antes dele, absolutamente novo e singular e que, ademais, tem relação com o valor [...]. Contudo, alguma coisa criada é sempre criada a partir de algo dado (a linguagem, o fenômeno observado da realidade, um sentimento vivenciado, o próprio sujeito falante, o acabado em sua visão de mundo, etc.). $\mathrm{O}$ dado inteiro se transforma em criado.

Isso significa que sempre há algo criado, constituído, com base em algo já existente, o dado, que também pode se configurar em uma "junção dialógica dos elementos multimodais" (BARONAS; ARAÚJO; PONSONI, 2013, p. 37). Assim sendo, a verbo-visualidade representa um modo de pensar a linguagem por meio das semioses verbal e visual, que proporcionam a construção de sentidos em um enunciado.

\section{Escola, juventudes e violência}

$\mathrm{Na}$ escola, a real diversidade dos alunos reduz-se ao cognitivo ou ao comportamento, muitas vezes tomado como elemento central dos processos escolares. Não são consideradas outras dimensões humanas dos sujeitos participantes da dinâmica social da escolarização, pois todos são tomados igualmente como alunos. Entretanto, a experiência e o contexto de vida dos jovens têm outros sentidos para a escolarização, nem sempre contemplados nos currículos e nas estruturas escolares. Os jovens não encontram consonância com as práticas escolares, porque possuem modos de ser e de viver que lhes são próprios. Os jovens são sujeitos de múltiplas trajetórias com historicidade, mundos de vida, valores, emoções, desejos, buscas pessoais etc. (LACERDA; AMARAL, 2018).

Ao refletir sobre a relação entre escola e juventudes, cabe observar que a sociabilidade é uma forte característica da condição juvenil, que também acontece em espaços institucionais como a escola e o trabalho, por exemplo. A dimensão da sociabilidade para os jovens pode responder a necessidades de comunicação, de solidariedade, de democracia, de autonomia, de trocas afetivas e, principalmente, de identidade, em relações de alteridade (DAYRELL, 2007).

As múltiplas trajetórias dos jovens levam-nos a saber coisas que a escola não sabe, a discutir e ter interesse em assuntos que não são abordados. Além disso, vivenciam conflitos e tensionamentos sociais, cuja reflexão ou mediação não acontece.

Os jovens que não conseguem viver em sintonia com um projeto naturalizado, hegemônico e consentido pela escola, acabam por ser colocados em uma situação de incompetência e de inferioridade (LACERDA; AMARAL, 2018, p. 96). 
Portanto, o sentido da escola é constituído com base nas trajetórias de seus sujeitos, cujas influências são o lugar de onde vêm, experiências, cultura e modos de vida (LACERDA; AMARAL, 2018).

Atualmente a exposição da juventude à violência é uma realidade indiscutível. A materialização dessa exposição acontece em um cotidiano de vulnerabilidade social. Trata-se de um cotidiano em que são notórias as carências relativas ao desenvolvimento educativo e cultural, que intervém nos problemas que a juventude atravessa na atualidade. A falta de oportunidade de trabalho para os adolescentes com mais de 18 anos e a diversificação de alternativas de lazer e de ambientes escolares incentivadores são exemplos de fatores que contribuem com o desenvolvimento dessa carência (GADEA et al., 2017).

Rodrigues e Santos (2018) comentam que os jovens também têm sido vítimas das consequências da desigualdade social no país. O tráfico de drogas é um dos maiores causadores do extermínio de jovens, pois gera guerras, onde está presente. Os jovens ingressam no universo do tráfico atraídos por falsos benefícios financeiros. O tráfico se torna um meio de sobrevivência, possibilitando a aquisição do que desejam, para não se sentirem socialmente inferiorizados por não possuírem.

Violência e Miséria não são fenômenos naturais nem fatalidades históricas permanentes, contrariamente, são fenô- menos originados da violação de direitos de uns sobre os demais. A violência se origina na desigualdade social, econômica e cultural, pois nem todos têm acesso à formação básica, para disporem de condições mínimas para realizar seus projetos de vida dignamente. Trata-se de um sistema estrutural movido por princípios distanciados de uma base ética capaz de garantir uma vida justa a todos, possibilitando um pleno exercício de cidadania (KUIAVA, 2012).

Para os jovens de classes populares, embora o ingresso seja universal, a permanência na escola tem se mostrado cada vez mais excludente, promovendo uma lógica de exclusão perversa. $\mathrm{O}$ processo de exclusão está para além da evasão e da reprovação, pois se situa na incorporação do aluno antes excluído, colocando-o em uma escolarização hierarquizada e degradada (PEREGRINO, 2004). Em uma realidade como esta, poucos conseguem superar os desafios e chegar até o final do processo, sem se perder no caminho (LACERDA; AMARAL, 2018). Sob essa perspectiva, a desigualdade é um fenômeno socioeconômico, e a exclusão é um fenômeno cultural e social (SANTOS, 1999).

Sob o direcionamento teórico referido, apresentamos a metodologia de pesquisa, informando sobre aspectos éticos, participantes e contexto do estudo e descrevendo o processo de geração de dados, para chegarmos aos dados em análise. 


\section{Metodologia}

O recorte de dados apresentados a seguir resulta da realização da primeira etapa da pesquisa "Novos Significados para Alunos dos Anos Finais do Ensino Fundamental no Contexto da Socioeducação: linguagens para autonomia e cidadania", coordenada pela professora Dra. Cátia de Azevedo Fronza, em andamento. Fazem parte desta investigação adolescentes dos anos finais do ensino fundamental e os professores da escola, com especial atenção aos docentes que atuam nas turmas de anos finais. Interessa-nos a participação de professores e alunos, em vista dos objetivos da pesquisa, pois compreendemos que o ensino em contexto socioeducativo se constitui por meio de um continuum, que inicia na formação do professor em direção à sua atuação no contexto de sala de aula.

Foi adotada uma abordagem qualitativa de cunho etnográfico (SILVERMAN, 2009; FLICK, 2009) e exploratória (PAIVA, 2019), cujo significado é produzido a partir dos dados gerados em campo (CRESWELL, 2007, p. 27).

A pesquisa da qual resulta este artigo teve seu projeto submetido ao Comitê de Ética em Pesquisa da Universidade do Vale do Rio dos Sinos (Unisinos), obtendo aprovação conforme CAEE 14998119.2.0000.5344, parecer $\mathrm{n}^{\mathrm{o}} 3.392 .065^{2}$.

Para compreender melhor o cenário da pesquisa, apresentamos o espaço, os participantes e o processo de geração de dados, para, em seguida, passarmos aos dados em análise.

\section{Espaço de pesquisa e participantes}

Conforme vem sendo descrito por Bastos (2019) e Bastos e Fronza (2020), o contexto de desenvolvimento da pesquisa está situado em uma escola da Rede Pública Estadual ${ }^{3}$, que presta atendimento escolar exclusivamente a adolescentes que estão em cumprimento de medida socioeducativa de internação.

Os participantes cujos dados têm foco neste artigo são adolescentes do sexo masculino e feminino, na faixa etária de 14 a 18 anos, em cumprimento de medida socioeducativa de internação, sem possibilidade de atividade externa (ISPAE). Estavam cursando os anos finais do ensino fundamental e apresentavam significativa defasagem idade-série. Haviam abandonado a escola há, em média, dois anos e retornaram, porque a escolarização é obrigatória ao adolescente durante o cumprimento de medida socioeducativa de internação.

\section{Processo de geração de dados}

Como já informado, a pesquisa encontra-se em andamento, embora, nesse momento de restrições quanto ao 
isolamento e distanciamento, em razão do plano de contingência em vigor pelo governo estadual, não tenhamos acesso à escola e aos alunos. Registramos que este trabalho se volta ao objetivo da referida pesquisa que visa a identificar interesses dos estudantes no que diz respeito vida, à escola, aos colegas e ao conhecimento possibilitado pela escola, como também verificar como percebem temas relacionados à educação, à violência e à sua inserção social com qualidade de vida.

Para este fim, foi planejado e aplicado pela equipe de pesquisa o instrumento de perspectiva exploratória, concretizado pela produção de representações multimodais. Tais produções foram propostas para que os adolescentes pudessem expressar seu ideal de escola, considerando suas vivências. Essas representações foram desenvolvidas com recortes de revistas, desenhos e escrita.

Os dados apresentados a seguir foram gerados, no horário das aulas, com oito turmas de adolescentes dos anos finais do ensino fundamental, seis turmas em unidades masculinas e duas em uma unidade feminina, totalizando 46 adolescentes do sexo masculino 17 do sexo feminino. Todas as interações realizadas no desenvolvimento da atividade foram gravadas em vídeo e transcritas. O processo de geração de dados ocorreu no período de setembro a dezembro de 2019.

Inicialmente, as atividades eram desenvolvidas por turma, em períodos de
90 minutos, para, na medida da necessidade, serem concluídas no dia seguinte. Como esse processo estava gerando certa morosidade, e os adolescentes perdiam o foco de um dia para o outro, passamos a ocupar os dois períodos de 90 minutos, abrangendo o turno de aula, com o desenvolvimento integral da atividade. Isso tornou mais ágil o processo, e os adolescentes mantinham-se mais engajados, contribuindo para a qualidade desse momento de geração de dados.

Para o desenvolvimento da atividade, a pesquisadora, primeiramente, convidou o professor titular da turma em seu respectivo horário de aula para participar da atividade, ficando à vontade para participar das interações com o grupo. Também contou com a ajuda do professor no desenvolvimento da atividade, para acompanhar e orientar a utilização dos materiais escolares, especialmente o uso das tesouras e do apontador.

No início da aula, a pesquisadora apresentou aos alunos a proposta da pesquisa, explicando-lhes o conhecimento que tal engajamento pode propiciar em relação ao contexto de escolarização em que eles se encontram, destacando a importância de cada um nesse processo. Depois disso, convidou-os a participar, apresentando outros detalhes com base no Termo de Assentimento Livre e Esclarecido ${ }^{4}$ (TALE). Uma vez que a participação é voluntária, um aluno, recém-chegado à internação optou por não participar da atividade. Os 
demais aderiram plenamente à proposta, demonstrando motivação e entusiasmo para contribuir com a pesquisa, em vista de se tratar de um projeto que envolve a sua escola.

Após os esclarecimentos e assentimentos confirmados, a pesquisadora e $o$ docente passaram a desenvolver com os adolescentes a construção de narrativas multimodais, com base no tema: "qual a escola ideal para você?”. O início da atividade foi motivado por um diálogo sobre o que, na sua opinião, havia de bom na escola, ou gostariam que houvesse, e o que havia de ruim ou o que não gostariam que a escola tivesse. Essa dinâmica foi produtiva, pois motivou os alunos ao desenvolvimento da atividade, mobilizando um repertório de ideias sobre a escola com base em suas vivências e percepções. Os professores que acompanharam a atividade, participaram do diálogo, motivando os adolescentes a refletirem e rememorarem suas vivências escolares.

Para o desenvolvimento da atividade, a pesquisadora forneceu aos alunos folhas de papel sulfite tamanho A3, lápis $6 \mathrm{~b}$, borracha, caneta, régua, tesoura, revistas, lápis de cor e canetas hidrocor. $\mathrm{O}$ fornecimento de material demandou controle em relação ao uso que os alunos iam fazendo, e os itens foram sendo entregues e guardados conforme o uso.

É necessário dizer que alguns alunos não desenvolveram a atividade multimodal, outros não quiseram comentar sobre sua produção. Quando isso acontecia, conversávamos, incentivávamos, sugeríamos o uso de determinados materiais. Se o adolescente mantinha seu posicionamento, respeitávamos e ele seguia assistindo a atividade, fazendo desenho livre ou lendo as revistas.

Em vista das limitações de espaço, desenvolveremos uma análise sobre a verbo-visualidade, em perspectiva dialógica, a partir de um recorte relativo à seleção de duas representações multimodais. Cabe destacar que a multimodalidade, neste artigo, é compreendida como a pluralidade de linguagens (ROJO; MOURA, 2019), mobilizadas para compor as representações, tais como: desenhos, elementos dos recortes de revista, como imagens, figuras, recortes de palavras e a forma de composição das palavras na linguagem escrita.

Como forma de sistematizar os dados analisados a seguir, apresentamos o Quadro 1 , com o nome fictício do adolescente participante, idade, ano escolar (série) e data da geração dos dados.

Quadro 1 - Informações sobre a autoria dos dados em análise

\begin{tabular}{|l|c|c|c|}
\hline $\begin{array}{c}\text { Nome } \\
\text { fictício }\end{array}$ & Idade & $\begin{array}{c}\text { Ano/ } \\
\text { totalidade }\end{array}$ & $\begin{array}{c}\text { Data da } \\
\text { geração de } \\
\text { dados }\end{array}$ \\
\hline Péricles & 18 anos & T5 (8 ano) & $05 / 11 / 2019$ \\
\hline Luana & 17 anos & T3 (6 ano) & $29 / 10 / 2019$ \\
\hline
\end{tabular}

Fonte: elaboração das autoras.

Conforme o Quadro 1 apresenta, selecionamos as representações desses dois jovens, um menino e uma menina, com 
idades entre 17 e 18 anos, para proceder à análise a seguir.

\section{Dados em análise}

O recorte de dados apresentado a seguir será analisado com base na Teoria das Representações Sociais (JODELET, 1993, 2017, 2018), em reflexões sobre juventudes, escola e violência (LACERDA; AMARAL, 2018; GADEA et al., 2017) e com atenção à verbo-visualidade, em perspectiva dialógica (BAKHTIN/ VOLOCHINOV, 2006; BRAIT, 2013; BARONAS; ARAÚJO; PONSONI, 2013).

As produções analisadas a seguir foram criadas com base no questionamento: qual seria a escola ideal para você? Como já anunciado, as referidas produções foram elaboradas no contexto de desenvolvimen- to da pesquisa "Novos Significados para Alunos dos Anos Finais do Ensino Fundamental no Contexto da Socioeducação: linguagens para autonomia e cidadania", em andamento, conforme descrito no tópico metodologia deste artigo. Na seção seguinte, procederemos à descrição, à análise e à interpretação das representações verbo-visuais. Cabe enfatizar que, quando há referência aos adolescentes participantes, utilizamos nomes fictícios, com o objetivo de preservar suas identidades.

\section{Representações multimodais sobre o ideal de escola dos adolescentes}

A primeira representação em foco é a de Péricles (Figura 2).

Figura 2 - Representação de Péricles

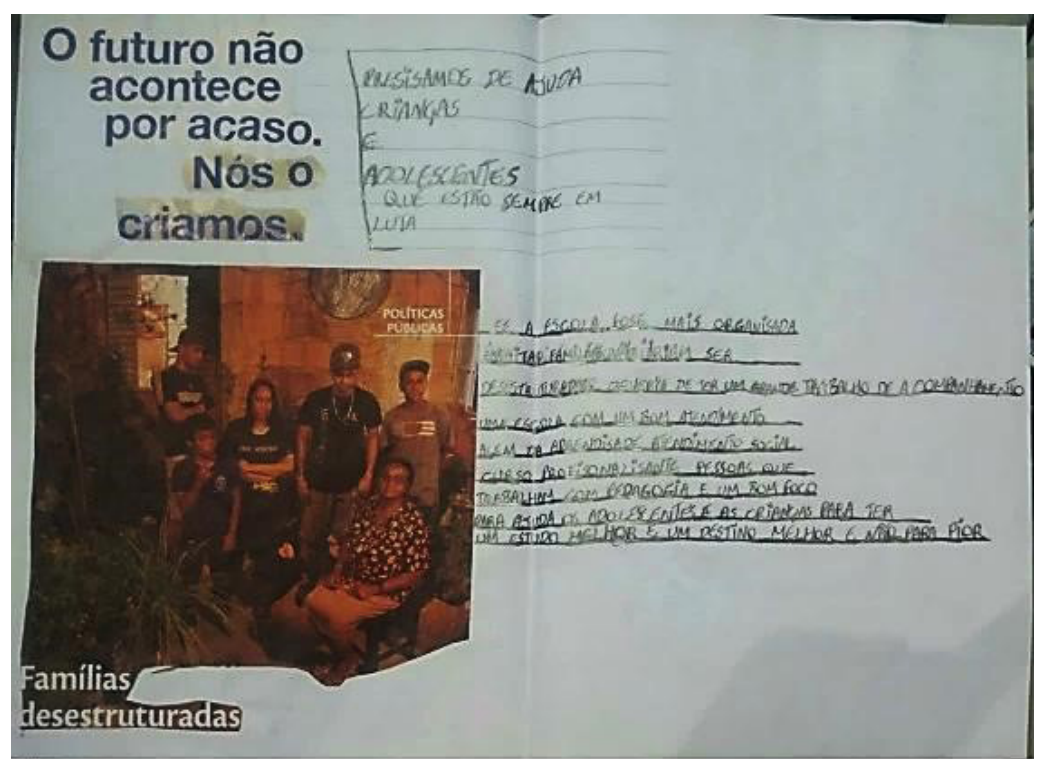

Fonte: dados da pesquisa. 
A perspectiva de Péricles, conforme Figura 2, com relação à escola parece não ser de idealização, mas de crítica. Ele se posiciona, por meio de uma montagem de palavras que resulta na seguinte afirmação "O futuro não acontece por acaso. Nós o criamos". Ao lado dessa ideia, escreve "PRECISAMOS DE AJUDA", em uma linha, e, nas linhas seguintes, diz: "CRIANÇAS E ADOLESCENTES QUE ESTÃO SEMPRE EM LUTA”. Em seguida, apresenta à esquerda da folha a colagem de uma imagem de uma família de classe popular com a frase "famílias desestruturadas, na parte inferior, e, na parte superior, a expressão "políticas públicas". Ao lado da imagem da família, ele escreveu: "Se a escola fosse mais organizada, muitas famílias não iriam ser desestruturadas. Deveria ter um grande trabalho de acompanhamento. Uma escola com bom atendimento. Além do aprendizado, atendimento social, curso profissionalizante, pessoas que trabalham com pedagogia e um bom foco, para ajudar os adolescentes e as crianças, para ter um estudo melhor e um destino melhor e não para pior". Durante a conversa sobre as colagens, Péricles não quis comentar sobre o seu trabalho.

O enunciado verbo-visual de Péricles não é uma expressão objetiva de algo existente fora dele, pois, ao esboçar o seu ideal de escola, parece criar uma ideia nova, com uma avaliação que parte de sua visão de mundo. A representação de escola ideal se materializa na verbo-visualidade a partir do diálogo entre um mundo de vida dado, constituído de linguagem, fenômenos observados da realidade, sentimentos vivenciados e a visão de mundo do sujeito, tornando-se o dado inteiro em criado (BAKHTIN, 2016). O diálogo entre o dado e o criado evidencia aspectos de tensão nas relações, por meio da confrontação entre os aspectos verbal e o visual, presentes nos registros, os quais se mostram como alteridades, pois, ao se defrontarem, constituem memórias de sujeitos e de objetos, possibilitando o surgimento de novas identidades (BRAIT, 2013).

Péricles pode querer mostrar uma perspectiva de futuro criada por si, ao estabelecer, por meio da montagem de frases, a negação sobre o futuro acontecer "por acaso", seguida da afirmação de que "nós o criamos". Criar um futuro para si, na perspectiva de Péricles, pode significar um anseio de quem compreende que participa de um sistema estrutural movido por princípios distanciados de uma base ética capaz de garantir uma vida justa a todos (KUIAVA, 2012). Em razão disso, o futuro com valores éticos tem que ser criado em um exercício de sobrevivência social que não acontece "por acaso".

Em seguida, expressa um pedido de ajuda, em que se inclui, ao se valer do verbo "precisar" em primeira pessoa 
do plural, trazendo ao diálogo o "nós" como pessoa do discurso, em que estão incluídos, crianças, adolescentes e ele, possivelmente como criança e adolescente crescendo em situação de risco social. O jovem acrescenta a expressão "que estão sempre em luta", parecendo remeter-se à ideia de que há uma "luta", que pode ser em sentido bélico, relativo ao envolvimento com o tráfico de drogas, ou no sentido de luta pela sobrevivência em situação de risco e vulnerabilidade social.

Péricles, ao afirmar que, "se a escola fosse mais organizada”, muitas famílias não seriam desestruturadas, posiciona sua crítica para além do estabelecimento escolar, direcionando-a para um horizonte social e histórico mais amplo, relativo à educação como instituição social. De certo modo, expressa um ponto de vista sobre a fragilidade do sistema educacional ao apontar que "deveria ter um grande trabalho de acompanhamento [...] um bom atendimento, além do aprendizado, atendimento social [...] pessoas que trabalham com a pedagogia e um bom foco [...] para ajudar os adolescentes e as crianças para ter um estudo melhor e um destino melhor e não para pior". Os destaques em itálico chamam atenção para termos que expressam avaliações do adolescente em relação ao modo como deveria estar organizada uma escola.

Péricles indica também que a escola deveria ter sua atenção para além do aprendizado, preocupando-se com o atendimento social, direcionado para a ação de ajudar crianças e adolescentes a se desenvolverem com mais qualidade e, em diálogo com a ideia de futuro, inicialmente enunciada, encaminha a ideia de estrutura de atendimento social como subsídio para um destino melhor.

Por fim, Péricles conclui sua reflexão estabelecendo uma avaliação, que possibilita compreender que a estrutura escolar atual pode contribuir com um destino/um futuro pior aos jovens. Essa compreensão pode estar fundamentada no fato de que a escola é representada como desorganizada, porque, no início do enunciado, ele apresenta uma oração subordinada condicional, "se a escola fosse mais organizada". Essa ideia nos remete à noção de escolarização hierarquizada e degradada (PEREGRINO, 2004), onde vagas para alunos são aumentadas sem que haja o devido investimento material e humano, necessário à adequada organização escolar (LACERDA; AMARAL, 2018).

A representação de escola ideal de Péricles parte de uma concepção crítica sobre a atuação da escola em diálogo com a experiência do adolescente, que pode ser inferida em sua representação, pois indica uma experimentação, a qual concorre para a construção da realidade, a partir de categorias socialmente dadas (JODELET, 2017). 
A expressão "CRIANÇAS E ADOLESCENTES QUE ESTÃO SEMPRE EM LUTA" não é uma simples frase, pois o sentido e a força da expressão, para além de expor uma ideia, está reiterado no formato da letra, embora escreva todo texto em maiúsculo, o enunciado inicial apresenta uma letra em tamanho maior, estabelecendo uma junção dialógica (BARONAS; ARAÚJO; PONSONI, 2013) entre letra, tamanho e disposição das palavras. Além disso, possibilita discutir as relações entre juventudes, violência e escola, tendo em vista que o enunciado faz referência a dois termos significativos em sua expressão, "ajuda e luta", associados aos termos "crianças e adolescentes". O enunciado verbo-visual, enquanto conjunto, na perspectiva dialógica, é revelador de autoria, de diferentes tipos de interlocuções e de discursos (BRAIT, 2013).

Assim sendo, a exposição dos jovens à violência urbana está relacionada a problemas de socialização que se iniciam no contexto familiar, no sentido de "famílias desestruturadas”, expresso por Péricles, e avança para o campo das carências materiais, educacionais, de inserção no mercado de trabalho e de dispositivos socialmente integradores, tais como o lazer, o esporte e demais atividades lúdicas, por exemplo, conforme explicam Gadea et al. (2017).
Rodrigues e Santos (2018) corroboram com essa análise, ao observarem que a juventude é vítima das consequências da desigualdade social. No contexto da violência urbana, o tráfico de drogas pode ser mais atraente do que a escola, pois os jovens ingressam nesse universo como meio de sobrevivência. Em vista de falsos benefícios oferecidos pelo tráfico, podem consumir sem se sentir inferiorizados diante de uma sociedade consumista, em que o mérito está no que se tem e não em quem se é. Ajuventude é a categoria cuja inserção no tráfico é crescente. Consequentemente, vem sofrendo com essa situação, convivendo com a violência, que se materializa no seu cotidiano.

As representações de Péricles convergem para relações de exclusão, pois, conforme Santos (1999), a desigualdade é um fenômeno socioeconômico e a exclusão um fenômeno sociocultural e social. $\mathrm{Na}$ realidade dos jovens de classes populares, o ingresso à escola é universal, mas a permanência, a cada dia que passa, é mais excludente. Embora a educação seja um direito universal, não está acessível a todos os níveis, para todas as pessoas, pois o acesso está reservado aos poucos que conseguem superar os desafios com base nos diferentes suportes a que têm acesso (LACERDA; AMARAL, 2018).

Após as reflexões suscitadas pelo registro de Péricles, a representação em foco passa a ser a de Luana (Figura 3). 
Figura 3 - Representação de Luana

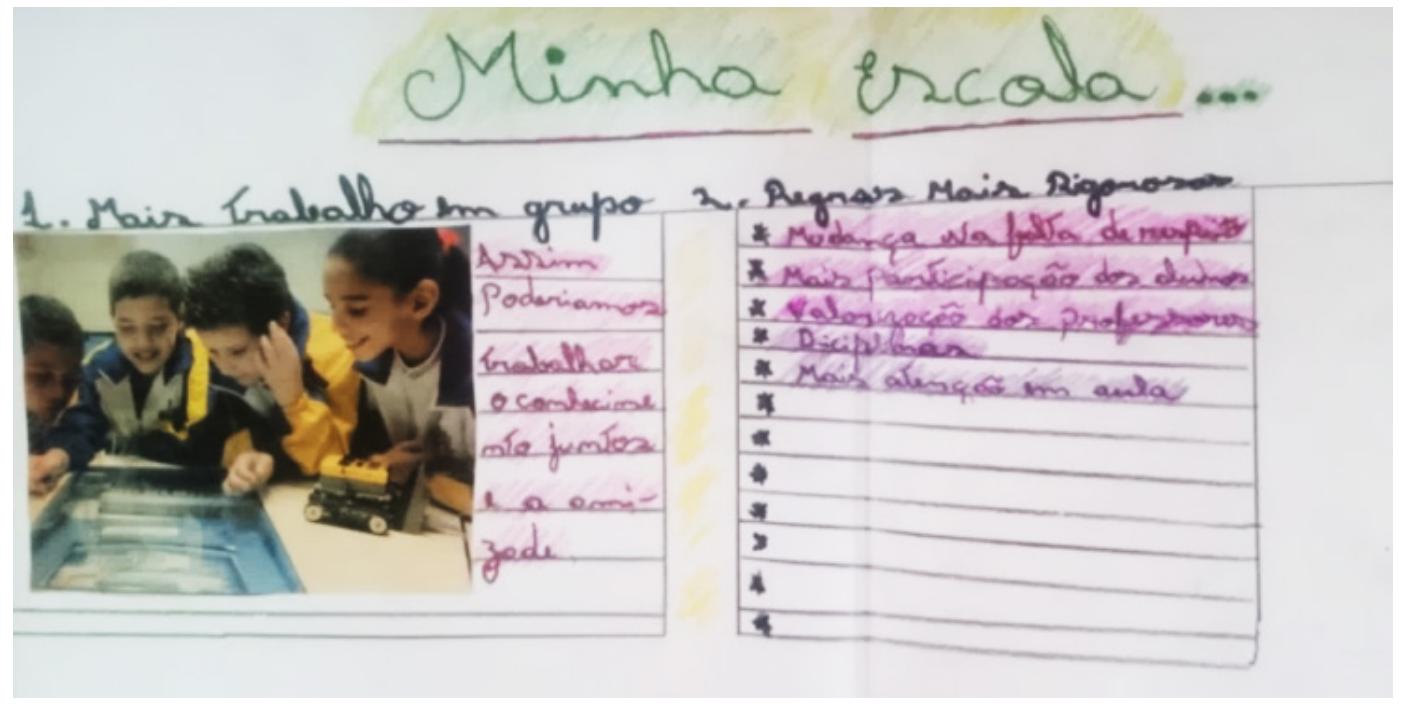

Fonte: dados da pesquisa.

Ao representar seu ideal de escola, Luana intitula de "minha escola" e desenvolve a proposta a partir de dois tópicos postos em paralelo: "1. Mais trabalho em grupo", que ilustra com uma imagem de crianças em um contexto escolar, reunidas em uma situação de aprendizagem. Nesse primeiro tópico apresenta o seguinte enunciado: "Assim poderíamos trabalhar o conhecimento juntos e a amizade".

$\mathrm{Na}$ segunda coluna, não há a inserção de imagem, apenas texto escrito, cujo tópico é "2. Regras mais rigorosas". Luana apresenta elementos que, na sua compreensão, devem ser contemplados pelas regras mais rigorosas, por meio de subtópicos demarcados com asteriscos: “*mudança na falta de respeito; *mais participação dos alunos; *valorização dos professores; *disciplinas; *mais atenção em aula". Ao propor mais trabalho em grupo, Luana usa o verbo "trabalhar" para estabelecer uma ação relativa ao conhecimento conjunto e à amizade.

A constituição verbo-visual da representação de escola ideal de Luana apresenta uma forma composicional que remete ao gênero do discurso lista de regras, pois, ao observar a Imagem 2 , podemos perceber que as dimensões verbal e visual atuam em conjunto, desempenhando um papel constitutivo na produção de sentido. A verbo-visualidade se dá a ler/ver de modo simultâneo. Não é possível, portanto, dissociar o verbal do visual, pois há o risco de extirparmos uma parte da expressão e eliminar a 
possibilidade de compreender as formas de produção de sentido do enunciado (BRAIT, 2013).

No momento de conversar sobre a representação feita, Luana explica que quer mostrar a escola como gostaria que fosse e menciona que gostaria que houvesse mais trabalho em grupo, "tipo, esse, agora assim, seria tri legal, porque daí trabalharia o conhecimento de todos juntos, assim, não separado e também trabalha um pouco da amizade, ne?, mais próximo". Seguiu, dizendo:

[...] tem mais coisas que eu quero botar, tem as regras... no colégio deveria ter mais regras assim, porque na sala de aula tem muita falta de respeito, ah, desordem, né, tudo desorganizado. Daí, tipo, poderia ter mudança no respeito, mais participação dos alunos, porque tem aluno que não presta atenção. Mais disciplina, valorização dos professores, mais atenção dos alunos.

Luana, ao representar sua escola ideal, valoriza o trabalho em grupo, tomando como exemplo a atividade que estava desenvolvendo no momento e justifica que a proximidade do trabalho em grupo favorece o desenvolvimento da amizade. Para ela, a convivência em grupo é algo desejado. Essa manifestação de Luana vai ao encontro do que Dayrell (2007) diz sobre o fato de que a sociabilidade, para os jovens, é um importante elemento, em vista de suas necessidades de comunicação, solidariedade, democracia, autonomia, trocas afetivas, como a amizade mencionada pela adolescente, e a identidade.
A leitura que ela tem do contexto de sala de aula, em termos de organização, não parece ser positiva, pois representa o espaço de sala de aula como sendo desorganizado, onde há falta de respeito e alunos desatentos. A adolescente parece mostrar esse espaço habitado por indivíduos que possuem interesses diversificados, com práticas de conflito, transgressões e enfrentamentos, formando um movimento processual de ressignificação do cotidiano escolar e de suas intencionalidades (DAYRELL, 2007; LACERDA; AMARAL, 2018). Luana acredita que os problemas existentes devido à diversidade escolar podem ser solucionados mediante o estabelecimento de "regras mais rigorosas", colo elementos organizadores das relações sociais.

Tomadas em conjunto, as representações de Péricles e Luana podem ser percebidas como fenômenos cognitivos, relacionados ao pertencimento social, às implicações afetivas e normativas, às interiorizações das experiências, das práticas, dos modelos de conduta e de pensamento, socialmente inculcados ou transmitidos pela comunicação social, que aí estão ligados (JODELET, 1993).

Considerando que a representação carrega a marca do sujeito e de sua atividade, como conteúdo concreto do ato de pensar e expressa um saber prático (JODELET, 1993), observamos na expressão dos termos "ajuda", "respeito" e "famílias desestruturadas" a constituição 
de um saber prático da realidade. Estes dois adolescentes em medida de internação, Péricles e Luana, parecem mostrar que seu saber se origina de suas vivências pessoais como adolescentes que transitam pelas vias de uma sociedade desigual (KUIAVA, 2012), traçando percursos nos caminhos da violência e do ato infracional. Os efeitos desse saber constituem suas representações verbo-visuais, por meio da junção dialógica dos elementos multimodais (BARONAS; ARAÚJO; PONSONI, 2013, p. 37), revelando autoria e diferentes tipos de interlocuções e de discursos, que constituem memórias de sujeitos e de objetos, possibilitando o surgimento de novas identidades, em relações de alteridade (BRAIT, 2013).

\section{Considerações finais}

Ao analisarmos as representações multimodais de Péricles e Luana, percebemos que a verbo-visualidade, expressa em suas representações, indica a existência de um diálogo social mais amplo, situado em um espaço extraverbal bakhtiniano. Nesse espaço, emergem questões contextuais que vão muito além da situação localizada do adolescente privado de liberdade, autor de ato infracional, refletindo sobre uma escola ideal. Deparamo-nos com a trama de relações entre escola, juventudes e violência, na perspectiva de uma sociedade desigual e excludente.
As representações multimodais analisadas parecem indicar o desejo de uma escola com mais qualidade de ensino e com valores humanos como respeito ao próximo e às diferenças. Assim sendo, a escola ideal se constitui em um ideal de mudança da realidade social dos jovens de periferia, das escolas e de capacidade de enfrentamento à violência, suportada por uma infraestrutura social que atenda às necessidades de lazer, educação e suporte social para os jovens e suas famílias.

Inserido no campo de estudos da Linguística Aplicada, este estudo, ao voltar-se à linguagem em uso, pode identificar particularidades discursivas, que apontam para contextos mais amplos, para um extralinguístico, relativo à exclusão e à violência. Muitas vezes consideradas por professores como questões "difíceis de lidar", a violência, o tráfico de drogas e os processos de exclusão vêm gradativamente permeando os muros da escola, promovendo situações de abandono escolar e lotando de jovens as unidades de atendimento socioeducativo. Entende-se aqui uma contribuição aos estudos da área, principalmente em vista da escassez de pesquisas em Linguística Aplicada sobre o contexto de ensino socioeducativo.

Assim, retomando nosso objetivo para este artigo, a análise das duas representações verbo-visuais sobre a escola ideal nos possibilitou um conhecimento maior sobre as construções de realidade 
desses adolescentes. São registros que apresentam muitos pontos em comum com outros registros que fazem parte do acervo da pesquisa e serão contemplados em outros estudos. Com relação à proposta de identificação de temáticas e abordagens de ensino mais significativas para esses jovens, o estudo nos oportunizou reconhecer a pluralidade desses jovens e reafirmar a necessidade de (re) pensar as práticas de ensino.

$\mathrm{O}$ ato de refletir sobre essas práticas tem relação com o fato de que a escola não pode ser mais um espaço de exclusão, a ação docente precisa conhecer as demandas dos alunos, para ser capaz de considerá-las especialmente em contexto socioeducativo. Essa perspectiva vai ao encontro do que foi identificado por Bastos (2019). A temática do "respeito", como apontado por Luana, envolve elementos de ordem social e cultural e pode ser explorada nas práticas de ensino. Entretanto, precisamos seguir com a pesquisa, para que possamos compreender como trabalhar o tema do respeito, entre tantos outros colocados à mostra pelos adolescentes, embora nem sempre vistos, de modo a promover os elos devidos entre conteúdos curriculares e prática social, para a formação da criticidade, da consciência e do pleno exercício da cidadania.

Ao se propor à identificação de temáticas e abordagens de ensino mais significativas aos adolescentes, este estudo não apresenta uma conclusão fechada em si, mas uma nova perspectiva de pesquisa que atribui ainda maior importância ao espaço de ensino em contexto socioeducativo, porém com um novo olhar para o aluno e sua historicidade. Quando Craidy (2015) afirma que a escola é um lugar para recuperar defasagens, frustrações e abandonos, dialoga com toda uma conjuntura social excludente de jovens de classes empobrecidas. Entretanto, o trabalho de recuperação/ inclusão, para além do desenvolvimento das práticas sociais de leitura e escrita, também perpassa a compreensão dos mundos de vida dos sujeitos envolvidos, manifestados na e pela linguagem. O diálogo entre a prática docente e a historicidade do adolescente é sempre necessário, ainda mais considerando o espaço da socioeducação, para que boas oportunidades de ensino e de aprendizagem se constituam como práticas reais.

\section{Representations about the ideal school for adolescents in the final years of elementary school in a socio-educational context}

\section{Abstract}

The infractions committed by adolescents in Brazil may be indicators of restricted access to fundamental rights, citizenship and social justice. The schooling of adolescents in social-educative sentences integrates the complex panorama of schooling 
of adolescents in the final years of primary school. Faced with this reality, the objective of this article is to analyze two verbal-visual representations about the ideal school, produced by adolescents serving social-educative sentences. The data were generated in a school from a large unit of social-educative detention in the south of the country, with adolescents deprived of freedom. The results of the analysis point to problems related to school, youth, and violence. Notes the importance of practice teaching dialogue with the historicity expressed in / by the language of young people, especially in the socio-educational teaching space, so that good teaching and learning opportunities, correspond to actual practices and can thus promote educational inclusion actions.

Keywords: Language. Verb-visuality. Adolescents in conflict with the law. Social-educative teaching context. Elementary school.

\section{Notas}

1 O projeto de pesquisa "Novos Significados para Alunos dos Anos Finais do Ensino Fundamental no Contexto da Socioeducação: linguagens para autonomia e cidadania” está sendo realizado com apoio e financiamento da Fundação Itaú Social em parceria com a Fundação Carlos Chagas, no âmbito do Edital de pesquisa anos finais do ensino fundamental: adolescências, qualidade e equidade na escola pública.

2 São considerados os preceitos legais estabelecidos nos artigos 17 e 94, inciso IV, do Estatuto da Criança e do Adolescente (ECA), Lei $\mathrm{n}^{\circ}$ 8.069/1990 (BRASIL, 1990). As Resoluções $\mathrm{n}^{\circ}$ 466/2012 e nº 510/2016 também são observadas, respaldando os cuidados éticos assumidos.

3 Por restrições de espaço, para que tenhamos foco nos dados, sugerimos a leitura de Bastos (2019) para detalhes sobre a configuração da escola na qual a pesquisa vem sendo realizada.
4 Os adolescentes por serem menores de idade assinaram o Termo de Assentimento Livre e Esclarecido (TALE). Os Termos de Consentimento Livre e Esclarecidos (TCLE) de cada um dos adolescentes participantes foram assinados com antecedência à entrada da equipe de pesquisa em sala de aula, pelo diretor do centro de atendimento onde se encontra $\mathrm{o}$ adolescente. $\mathrm{O}$ encaminhamento dos TCLEs para assinatura foi realizado pela diretora da escola, membro da equipe de pesquisa.

\section{Referências}

BASTOS, S. C. M. "Na escola, o cara tinha que ficá quieto, olhando pro quadro e escrevendo. Na rua, eu fazia o que eu queria": fenômenos representativos de adolescentes em conflito com a lei sobre as aulas de língua materna, escolarização e abandono escolar. 2019. 107 f. Dissertação (Mestrado em Linguística Aplicada) - Programa de Pós-Graduação em Linguística Aplicada, Universidade do Vale do Rio dos Sinos (UNISINOS), São Leopoldo, 2019.

FRONZA, C de A. Novos Significados para Alunos dos Anos Finais do Ensino Fundamental no Contexto da Socioeducação: linguagens para autonomia e cidadania. 2019. 31 p. Projeto de Pesquisa. Edital de pesquisa anos finais do ensino fundamental: adolescências, qualidade e equidade na escola pública. Fundação Itaú Social e Fundação Carlos Chagas. São Paulo, 2018.

BASTOS, S. C. M.; FRONZA, C. DE A. Fenômenos representativos de adolescentes em contexto socioeducativo sobre escolarização, abandono escolar e aulas de língua materna. Letras de Hoje, v. 55, n. 3, p. e36567, 11 dez. 2020.

BAKHTIN, M. (VOLOCHÍNOV, V. N.). Marxismo e filosofia da linguagem. Problemas fundamentais do método sociológico na ciência da linguagem. 12. ed. Trad. Michel Laud e Yara F. Vieira. São Paulo: Hucitec, 2006. 
BAKHTIN, M. Os gêneros do discurso. Trad. Paulo Bezerra. São Paulo: Editora 34, 2016.

BARONAS, R. L.; ARAÚJO, L. M. B. M; PONSONI, S. Reflexões acerca da análise dialógica dos discursos verbo-visuais: um caso de humor na política brasileira. Bakhtiniana, São Paulo, v. 8, n. 2, p. 24-42, jul./ dez. 2013.

BRAIT, B. Olhar e ler: verbo-visualidade em perspectiva dialógica. Bakhtiniana, São Paulo, v. 8, n. 2, p. 43-66, jul./dez. 2013.

BRASIL. Lei no 8069, de 1990. Dispõe sobre o Estatuto da Criança e do Adolescente e dá outras providências. Brasília, DF, 1990. Disponível em: http://www.planalto.gov.br/ccivil_03/ leis/18069.htm. Acesso em: 17 nov. 2019.

BOZZA, M. Os sentidos da "escola inserida" para os jovens privados de liberdade: cada dia é um dia. In: STECANELA, N. (org.). Ler e escrever a vida: trajetórias de jovens em privação de liberdade. Caxias do Sul: Educs, 2012. Cap. 5. p. 93-115.

COMERLATO, D. Letramento, Alfabetização e Vulnerabilidade Social. In: CRAIDY, C. M.; SZUCHMAN, K. (org.). Socioeducação: fundamentos e práticas. Porto Alegre: Evangraf, 2015. p. 90-95.

CRAIDY, C. M. Medidas Socioeducativas e Educação. In: CRAIDY, C. M.; SZUCHMAN, K. (org.). Socioeducação: fundamentos e práticas. Porto Alegre: Evangraf, 2015. p. 74-89.

CRAIDY, C. M. Medidas socioeducativas e direitos: o paradigma do jovem infrator como sujeito de direitos. In: STECANELA, N. (org.). Ler e escrever a vida: trajetórias de jovens em privação de liberdade. Caxias do Sul: Educs, 2012. Cap. 2. p. 47-60.

CRESWELL, J. W. Projeto de pesquisa: métodos qualitativo, quantitativo e misto. 2. ed. Porto Alegre: Artmed/Bookman, 2007.

DAYRELL, J. A escola "faz" as juventudes? reflexões em torno da socialização juvenil. Educação \& Sociedade, Campinas, v. 28, n. 100 - Especial, p. 1105-1128, out. 2007.
FLICK, U. Introdução à pesquisa qualitativa. 3. ed. Tradução: Joice Elias Costa. São Paulo: Artmed, 2009.

GADEA, C. A. et al. Trajetórias de jovens em situação de vulnerabilidade social: sobre a realidade juvenil, violência intersubjetiva e políticas para jovens em Porto Alegre - RS. Sociologias, Porto Alegre, ano 19, n. 45, p. 258-299, maio/ago. 2017.

JODELET, D. Ciências sociais e representações: estudo dos fenômenos representativos e processos sociais, do local ao global. Revista Sociedade e Estado, v. 33, n. 2, p. 423-442, maio/ago. 2018. Tradução: José Geraldo de Oliveira Almeida.

JODELET, D. Representações Sociais e Mundos de Vida. Tradução: Lilian Ulup. Edição: Nikos Kalampalikis. São Paulo: Fundação Carlos Chagas; Curitiba: PUCPRess, 2017.

JODELET, D. Représentations sociales: um domaine em expansion. In: JODELET, D. (org). Les Représentations sociales. Paris: PUF, 1989. p. 31-61. Tradução: Tarso Bonillha Mazzotti. Revisão Técnica: Alda Judith Alves-Mazzotti. UFRJ - Faculdade de Educação, dez. 1993. Uso escolar, proibida a reprodução.

KUIAVA, A. E. Ética e Ato Infracional: interfaces do humano. In: STECANELA, N. (org.). Ler e escrever a vida: trajetórias de jovens em privação de liberdade. Caxias do Sul: Educs, 2012. Cap. 5. p. 93-115.

LACERDA, M. P. C. de; AMARAL, M. de F. Juventudes e Direito à Educação: aproximações a um tema complexo. In: PERONDI, M. et al. (org.). Infâncias, adolescências e juventudes na perspectiva de direitos humanos: onde estamos? Para onde vamos? Porto Alegre: EDIPUCRS, 2018. p. 89-104.

OSTERMANN, A.; GUIMARÃES, A. M. M. A Linguística Aplicada que se faz 'aqui': dez anos formando doutoras e doutores. Calidoscópio, v. 17, n. 4, dez. 2019. 
PAIVA, V. L. M. de O. Manual da Pesquisa em Estudos Linguísticos. São Paulo: Parábola, 2019.

PEREGRINO, M. A fecundidade da noção de moratória (vital/social) para análise das relações entre juventude e educação no contexto da massificação dos processos educativos. Textos Completos, 27. Caxambu: Reunião ANPED, 2004. Disponível em: http://www. anped.org.br/sites/default/files/t0313.pdf. Acesso em: 15 jul. 2020.

RODRIGUES, K. A.; SANTOS, W. S. Contribuições para o acesso e permanência na escola do jovem vítima da violência urbana por meio do trabalho multidisciplinar. In: PERONDI, M. et al. (org.). Infâncias, adolescências e juventudes na perspectiva de direitos humanos: onde estamos? Para onde vamos?. Porto Alegre: EDIPUCRS, 2018. p. 121-138.

ROJO, R.; MOURA, E. Letramentos, Mídias, Linguagens. São Paulo: Parábola, 2019.

SANTOS, Boaventura de Souza. A construção da igualdade e da diferença. Oficina. CES, Rio de Janeiro, n. 135, 1999. Disponível em: www.ces.uc.pt/publicacoes/oficina/ ficheiros/135.pdf. Acesso em: 31 mar. 2018.

SILVERMAN, D. Interpretação de dados qualitativos. Tradução: Magda França Lopes. Porto Alegre: Artmed, 2009.

VOLPI, M. Educação em direitos humanos na socioeducação. In: MENEZES, M. M. de et al. (org.). Direitos humanos em debate: educação e marcadores sociais da diferença. Porto Alegre: Cirkula, 2019. p. 195-203.

WILSON, A. "Go to Get Away from the Cockroaches": Educentricity and the Politics of Education in Prisons. The Journal of Correctional Education, v. 58, 2 June 2007. 